\title{
Dynamic Ligand Exchange in Reactions of Samarium Diiodide
}

\author{
Dhandapani V. Sadasivam, ${ }^{\dagger}$ Joseph A. Teprovich, Jr., ${ }^{\dagger}$ David J. Procter, ${ }^{\ddagger}$ and \\ Robert A. Flowers, II,
}

Department of Chemistry, Lehigh University, Bethlehem, Pennsylvania 18015, and

School of Chemistry, University of Manchester, Manchester M13 9PL, U.K.

rof2@lehigh.edu

Received July 23, 2010

\section{ABSTRACT}

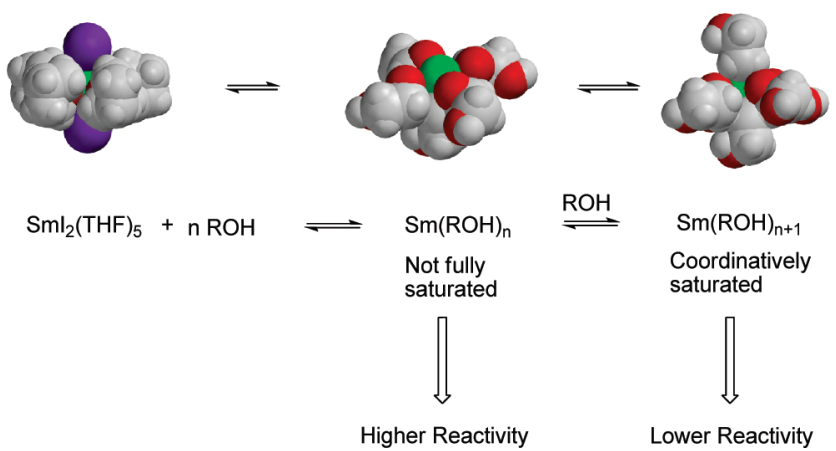

Mechanistic studies show the importance of iodide displacement by additives that accelerate reactions of samarium diiodide. The key feature important for acceleration of reaction rate is the use of proton donors and other additives that have a high enough affinity for Sm(II) to displace iodide yet do not saturate the coordination sphere inhibiting substrate reduction.

The presence of additives is essential for the success of many reactions initiated by samarium diiodide $\left(\mathrm{SmI}_{2}\right) .{ }^{1}$ Lewis bases, such as HMPA, have a mechanistically complex effect on reactions. Although HMPA is the additive of choice in many reactions of $\mathrm{SmI}_{2}$, alcohols and other additives can be used successfully in some cases to provide high yielding and

\footnotetext{
† Lehigh University.

University of Manchester.

(1) (a) Procter, D. J.; Flowers, R. A., II; Skrydstrup, T. Organic Synthesis Using Samarium Diiodide: A Practical Guide; Royal Society of Chemistry Publishing: U.K., 2010. (b) Nicolaou, K. C.; Ellery, S. P.; Chen, J. S. Angew. Chem., Int. Ed. 2009, 48, 7140-7165. (c) Flowers, R. A., II. Synlett 2008, 1427-1439. (d) Flowers, R. A., II; Prasad, E. In Handbook on the Physics and Chemistry of Rare Earths; Gschneidner, K. A., Jr.; Bunzli, J.-C. G.; Pecharsky, V. K., Eds.; Elsevier: Amersterdam, 2006; Vol. 36, pp 393-473. (e) Berndt, M.; Gross, S.; Hölemann, A.; Reissig, H.-U. Synlett 2004, 422 438. (f) Edmonds, D. J.; Johnston, D.; Procter, D. J. Chem. Rev. 2004, 104, 3371-3403. (g) Dahlén, A.; Hilmersson, G. Eur. J. Inorg. Chem. 2004 3393-3403. (h) Kagan, H. B. Tetrahedron 2003, 59, 10351-10372. (i) Steel, P. G. J. Chem. Soc., Perkin Trans. 1 2001, 2727-2751. (j) Krief, A.; Laval, A.-M. Chem. Rev. 1999, 99, 745-777. (k) Molander, G. A.; Harris, C. R. Chem. Rev. 1996, 96, 307-338. (1) Molander, G. A. Chem. Rev. 1992, 92, $29-68$.
}

selective reaction processes. ${ }^{1 \mathrm{c}}$ Understanding the mechanistic details of alternative approaches to enhancing the reactivity and selectivity of $\mathrm{SmI}_{2}$-based reactions would allow chemists to design methods for accelerating reductions while avoiding the use of HMPA. Herein we show that the use of ligands that displace iodide but do not saturate the coordination sphere of Sm(II) provides a mechanistic pathway for accelerating the rate of electron transfer from $\mathrm{SmI}_{2}$.

In understanding possible approaches to developing alternative means to facilitate electron transfer from $\mathrm{SmI}_{2}$, it is useful to consider the mechanism of action of successful additives. In the case of HMPA, coordination to $\mathrm{SmI}_{2}$ produces a stronger reductant, and simultaneous displacement of the iodide ligands creates open coordination sites for substrates while concomitantly producing a sterically encumbered reductant. ${ }^{2}$ Proton donors including water, alco-

(2) (a) Prasad, E.; Flowers, R. A., II. J. Am. Chem. Soc. 2002, 124, 6895-6899. (b) Prasad, E.; Knettle, B. W.; Prasad, E.; Flowers, R. A., II. J. Am. Chem. Soc. 2004, 126, 6891-6894. 
hols, and glycols also accelerate reactions. Addition of large amounts of water to $\mathrm{SmI}_{2}$ in THF creates a thermodynamically stronger reductant, but most alcohols do not. ${ }^{3}$ Work by Hilmersson has shown that glycols are more effective than alcohols because they can chelate $\mathrm{SmI}_{2}{ }^{4}$ Recent studies by Hoz show that alcohols accelerate reductions of carbonyls through coordination to $\mathrm{SmI}_{2}$, which places the proton donor in close proximity to the developing negative charge on the substrate being reduced, thus facilitating rapid proton transfer. $^{5}$

Although many alcohols accelerate the reduction of carbonyls, water is different in that it significantly increases the rate of reduction of alkyl halides and other substrates. The unusual mechanistic behavior of water is in part a consequence of its high affinity for $\mathrm{SmI}_{2}$ and its ability to increase the ease of oxidation of $\mathrm{SmI}_{2} \cdot{ }^{2,6}$ Other high affinity proton sources such as diethylene glycol (DG) accelerate reactions of $\mathrm{SmI}_{2}$ in smaller amounts, but unlike water, larger amounts create a reductant with a saturated coordination sphere that retards the rate of substrate reduction. ${ }^{7}$ In considering the unusual effect of water, could its mechanism of action be similar to that of HMPA? While water is capable of increasing the reducing power of $\mathrm{SmI}_{2}$ (similar to HMPA), the other key component of HMPA addition to $\mathrm{SmI}_{2}$ is displacement of iodide to produce coordination sites for substrates. Does water displace iodide from $\mathrm{SmI}_{2}$ and accelerate reductions?

One of the difficulties in examining $\mathrm{SmI}_{2}$-additive systems is the stability of the intermediate formed. Addition of HMPA and some glycols provides crystals that can be readily isolated and analyzed. These studies show that HMPA, DG, glymes, and other additives displace iodide to the outer sphere. ${ }^{7-10}$ While attempts to isolate crystals of $\mathrm{SmI}_{2}-\mathrm{H}_{2} \mathrm{O}$ have been unsuccessful, crytallographic data does not always mirror solution structures. Solution chemistry is a dynamic process and insight into the role of additives on the structure of $\mathrm{SmI}_{2}$ in solution is critical to understanding the impact of additives on the reactivity of the reagent. To date, only the solution structures of $\mathrm{SmI}_{2}-\mathrm{HMPA}$ complexes have been examined. ${ }^{11}$ The seminal work of Daasbjerg and Skrydstrup used conductance measurements as a means to unravel the role of HMPA on $\mathrm{SmI}_{2}$ in THF. ${ }^{1 \mathrm{~b}}$ Their studies are consistent with iodide displacement from $\mathrm{SmI}_{2}$ upon the addition of HMPA.

(3) (a) Chopade, P.; Prasad, E.; Flowers, R. A., II. J. Am. Chem. Soc. 2004, 126, 44-45. (b) Prasad, E.; Flowers, R. A., II. J. Am. Chem. Soc. 2005, 127, 18093-18099.

(4) Dahlén, A.; Hilmersson, G. Tetrahedron Lett. 2001, 42, 5565-5569.

(5) (a) Farran, H.; Hoz, S. J. Org. Chem. 2009, 74, 2075-2079. (b) Amiel-Levy, M.; Hoz, S. J. Am. Chem. Soc. 2009, 131, 8280-8284.

(6) Dahlén, A.; Hilmersson, G.; Knettle, B. M.; Flowers, R. A. J. Org. Chem. 2003, 68, 4870-4875.

(7) Teprovich, J. A., Jr.; Balili, M. N.; Pintauer, T.; Flowers, R. A. Angew. Chem., Int. Ed. 2007, 46, 8160-8163.

(8) Hou, Z.; Zhang, Y.; Wakatsuki, Y. Bull. Chem. Soc. Jpn. 1997, 70, 149-153.

(9) Teprovich, J. A., Jr.; Prasad, E.; Flowers, R. A., II. Angew. Chem., Int. Ed. 2007, 46, 1145-1148.

(10) Vestergren, M.; Gustafsson, B.; Johansson, A.; Håkansson, M. J. Organomet. Chem. 2004, 689, 1723-1733.

(11) (a) Shotwell, J. B.; Sealy, J. M.; Flowers, R. A., II. J. Org. Chem. 1999, 64, 5251-5255. (b) Enemærke, R. J.; Hertz, T.; Skrydstrup, T.; Daasbjerg, K. Chem.-Eur. J. 2000, 6, 3747-3754.
To begin to address the role of water and other additives in solution, conductance experiments were initiated to assess the impact of different additives on iodide displacement (Figure 1). Initially, HMPA was used to benchmark the

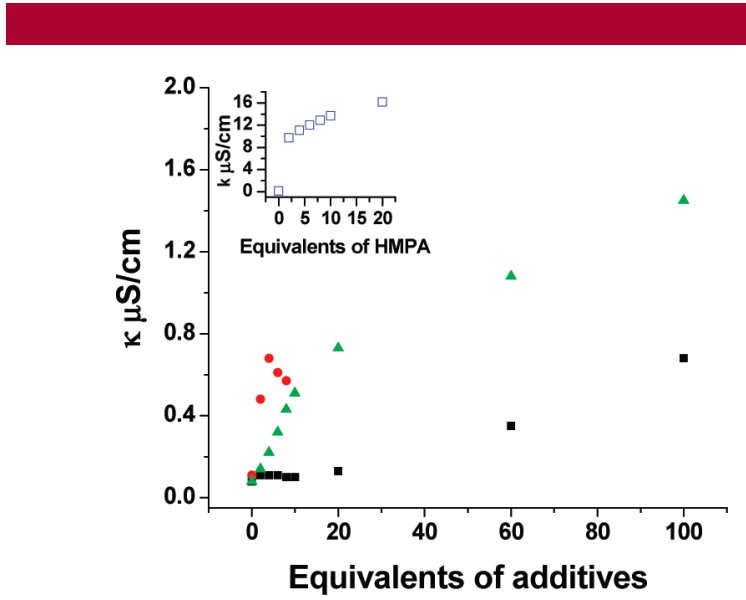

Figure 1. Plot of the conductivity of $2.5 \mathrm{mM} \mathrm{SmI}_{2}$ with increasing amounts of DG ( $)$ red), EG ( $\mathbf{\Delta}$; green), and $\mathrm{H}_{2} \mathrm{O}$ ( $\boldsymbol{\square}$; black); the inset shows HMPA ( $\square$; blue).

system. The conductivity of $\mathrm{SmI}_{2}$ in THF was zero. Upon addition of HMPA, the conductance of the solution increased substantially with the addition of 2 equiv. Further addition of HMPA increased the conductance of the solution, but to a lesser extent (inset, Figure 1). Similarly, addition of DG to $\mathrm{SmI}_{2}$ increased the conductance of the solution substantially up to 6 equiv and then decreased due to precipitation of the complex. Addition of ethylene glycol (EG) to a solution of $\mathrm{SmI}_{2}$ showed an increase in conductance up to 20 equiv and then increased more gradually with further addition up to 100 equiv. Addition of water had no impact at low concentrations, and the conductance of the solution began to increase only after the addition of more than 20 equiv of water. The solution conductance increased gradually with addition of 100 equiv of water. The changes in solution conductivity are consistent with iodide displacement by each additive examined. ${ }^{11 \mathrm{~b}}$

To further characterize the $\mathrm{SmI}_{2}$-additive combinations, we examined the UV-vis spectra of complexes formed with additives shown by conductance to displace iodide from the inner-sphere of $\mathrm{SmI}_{2}$. Figure 2 contains the UV-vis spectra of $\mathrm{SmI}_{2}$ in THF containing 15 equiv of HMPA, 8 equiv of DG, 100 equiv of EG, and 500 equiv of water, respectively. In the first two cases, the displacement of iodide from the inner sphere of $\mathrm{Sm}(\mathrm{II})$ has been confirmed by crystallographic evidence. ${ }^{7,8}$

The feature that each of these spectra have in common is the appearance of an absorption at approximately $480 \pm 10$ nm. Titrations of $\mathrm{SmI}_{2}$ with each additive showed the formation of the peak at $480 \mathrm{~nm}$ at concentrations shown to displace iodide in conductance experiments. Addition of HMPA to $\mathrm{SmI}_{2}$ also shows a shoulder at $480 \mathrm{~nm}$ on a broader absorption at $550 \mathrm{~nm}$ that begins to appear with the addition of 4 equiv of HMPA. While we are not assigning the 


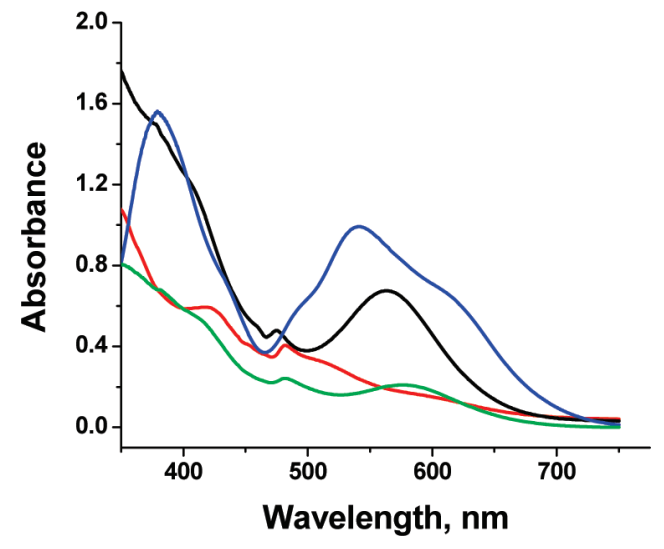

Figure 2. UV-vis spectra of (a) $1 \mathrm{mM} \mathrm{SmI}_{2}$ in $\mathrm{THF}+15$ equiv HMPA (blue), (b) $1 \mathrm{mM} \mathrm{SmI}_{2}$ in THF containing 500 equiv of of water (black), (c) $1 \mathrm{mM} \mathrm{SmI}_{2}$ in THF +8 equiv of DG (red), and (d) $1 \mathrm{mM} \mathrm{SmI}_{2}$ in THF +100 equiv of $\mathrm{EG}$ (green).

absorption at 480 as iodide "free" $\mathrm{Sm}$ (II), the appearance of this band is concomitant with concentrations of additives shown by conductance measurements to displace iodide from the inner sphere of the metal. As a consequence, the UV-vis spectra can be used as a guide to examine the impact of other additives on $\mathrm{SmI}_{2}$ (vide infra).

Rate data from previous studies on DG and related additives shows that saturation of Sm leads to a decrease in reactivity. ${ }^{7}$ Comparison with data from previous studies on water indicate that even high concentrations of water do not lead to complete saturation of $\mathrm{Sm}(\mathrm{II}){ }^{3}$ If this supposition is correct, it shows that the impact of water is in part a result of providing open coordination sites without saturating the metal as exemplified in Scheme 1.

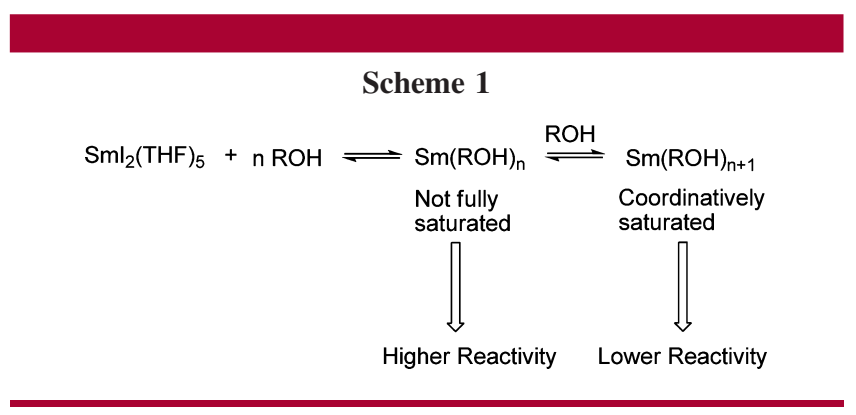

The work of Procter has shown that a number of unique and synthetically important reductions can be initiated by $\mathrm{SmI}_{2}$ containing high concentrations of water. ${ }^{12}$ Although water provides access to exceptional reactivity at high concentrations, $\mathrm{SmI}_{2}$ - water systems oxidize readily, and working with them can be difficult. The collection of data above suggests that other additives can be employed in place of water.

(12) (a) Duffy, L. A.; Matsubara, H.; Procter, D. J. J. Am. Chem. Soc. 2008, 130, 1136-1137. (b) Guazzelli, G.; De Grazia, S.; Collins, K. D.; Matsubara, H.; Spain, M.; Procter, D. J. J. Am. Chem. Soc. 2009, 131, 72147215. (c) Parmar, D.; Duffy, L. A.; Sadasivam, D. V.; Matsubara, H.; Bradley, P. A.; Flowers, R. A., II; Procter, D. J. J. Am. Chem. Soc. 2009, $131,15467-15473$.
Conductance data showed that addition of EG to $\mathrm{SmI}_{2}$ liberates iodide. Since it is bidentate, it should have an affinity intermediate between water and DG. As a consequence reduced amounts of EG (compared to water) should be required to induce iodide displacement and enhance reactivity but not have such a high affinity that it produces a substitutionally inert complex. Although this additive has been used in a range of $\mathrm{SmI}_{2}$-based reductions, its mechanism of action has not been examined. ${ }^{13}$ To further probe the system, kinetic experiments were performed to investigate the role of concentration on the reduction of a model substrate benzyl bromide. ${ }^{14}$ The impact of EG and water concentration on the rate of reduction was monitored and is shown in Figure 3. Both additives exhibit saturation kinetics

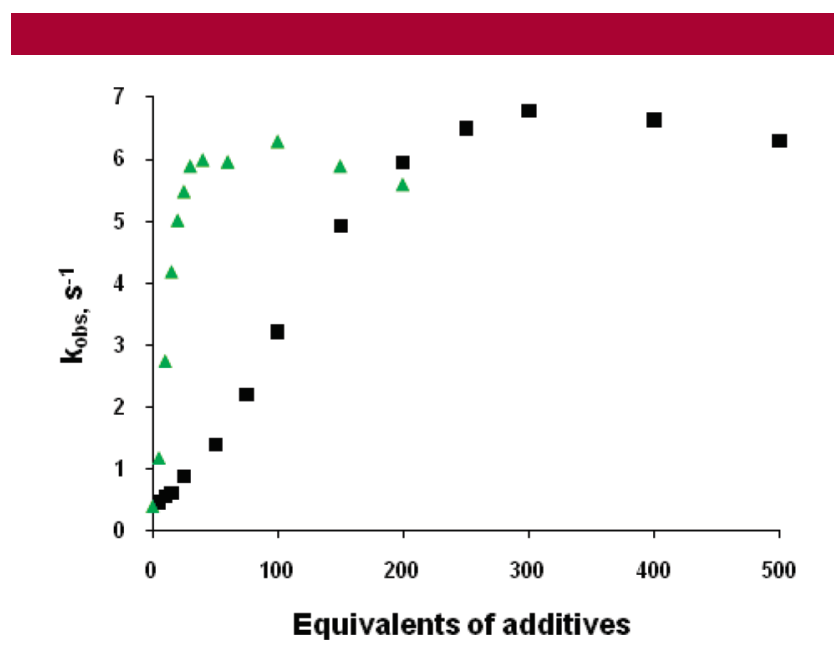

Figure 3. Plot of $k_{\text {obs }}$ versus EG ( $\boldsymbol{\Delta}$; green) and $\mathrm{H}_{2} \mathrm{O}$ ( $\mathbf{\square}$; black) for the reduction of benzyl bromide $(100 \mathrm{mM})$ by $\mathrm{SmI}_{2}(2 \mathrm{mM})$.

and substantially increase the rate of reduction, but EG increases the rate at lower concentrations than water. Unlike water, which shows complex rate orders for the reaction, ${ }^{3}$ reductions using EG were first order in additive, $\mathrm{SmI}_{2}$, and substrate.

The experiments described above show that addition of water and $\mathrm{EG}$ to $\mathrm{SmI}_{2}$ displace iodide in THF. The affinity of each additive for $\mathrm{SmI}_{2}$ in THF dictates the amount necessary to displace bulk solvent and iodide from the inner sphere of Sm. Kinetic studies show that water and EG increase the rate of substrate reduction substantially and the rate of the increase is concomitant with iodide displacement. In contrast, additives like DG that have a very high affinity for $\mathrm{SmI}_{2}$ initially enhance the rate of substrate reduction, but continued addition decreases the rate of reduction through the saturation of the coordination sphere of the metal thus inhibiting the ability of substrate to interact with $\mathrm{Sm} .{ }^{6}$ The

(13) (a) Hanessian, S.; Girard, C. Synlett 1994, 863-864. (b) Linderman, R. J.; Cusack, K. P.; Kwochka, W. R. Tetrahedron Lett. 1994, 35, 14771480. (c) Tarnopolsky, A.; Hoz, S. J. Am. Chem. Soc. 2007, 129, 34023407.

(14) Benzyl bromide was chosen as a model substrate to simplify the kinetic analysis. (a) Andrieux, C. P.; Gallardo, I.; Saveant, J.-M.; Su, K.B. J. Am. Chem. Soc. 1986, 108, 638-647. (b) Saveant, J.-M. J. Am. Chem. Soc. 1987, 109, 6788-6795. 
collection of these data suggests that water, EG, and other additives capable of displacing iodide from Sm while leaving open coordination sites for substrate provide a means to enhance the reactivity of $\mathrm{SmI}_{2}$ significantly.

The fundamental question remains: is this a viable approach for determining adequate substitutes for water and, additionally, for HMPA? First, we examined whether another additive could be employed to promote transformations that have only been reported with water. ${ }^{12}$ To address this issue, the reduction of lactone 5-decanolide $\mathbf{1}$ by $\mathrm{SmI}_{2}$ and $\mathrm{EG}$ was examined and compared to the known reduction by $\mathrm{SmI}_{2}-$ water (Table 1). Addition of $\mathrm{EG}$ to $\mathrm{SmI}_{2}$ provided reduction

Table 1. Reduction of 5-Decanolide with Water and EG

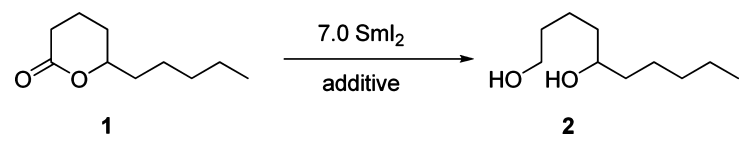

\begin{tabular}{cccc}
\hline entry & additive, equiv & time $(\mathrm{h})$ & isolated yield $\mathbf{2}(\%)$ \\
\hline 1 & $\mathrm{H}_{2} \mathrm{O}, 150$ & 7 & 83 \\
2 & $\mathrm{EG}, 4$ & 12 & 80 \\
\hline
\end{tabular}

of $\mathbf{1}$ similar to water at much lower additive concentrations. Although higher concentrations of EG accelerated the rate of reaction, transesterification became the major product.

Since this approach can potentially be used to promote reactions that only worked with $\mathrm{SmI}_{2}$-water, ketone-alkene cyclizations were examined to determine if this method could be applied to more complex bond-forming reactions that employ HMPA. ${ }^{15,16}$ 2-But-3-enyl-cyclohexan-1-one 3 was treated with $\mathrm{SmI}_{2}$ in the presence (and absence) of HMPA, EG, and $\mathrm{H}_{2} \mathrm{O}$. The results are shown in Table 2. Addition of 4 equiv of HMPA provided excellent yield of $\mathbf{4}$ with very good diastereoselectivity. ${ }^{15,17}$ The use of 150 equiv of water and 24 equiv of EG (based on $\left[\mathrm{SmI}_{2}\right]$ ) provided excellent yields of cyclized product $\mathbf{4}$ with modest diastereoselectivity. Although lower concentrations of EG provided good yields of $\mathbf{4}$, higher amounts of reduced product 5 were obtained. Interestingly, the same trend was observed with water although this additive accelerated the reaction significantly compared to EG.

Although water and EG were effective in the ketone-alkene cyclization, diastereoselectivities were modest. To determine

(15) Molander, G. A.; McKie, J. A. J. Org. Chem. 1992, 57, 31323139.

(16) Saadi, J.; Lentz, D.; Reissig, H. U. Org. Lett. 2009, 11, 33343337.

(17) Sadasivam, D. V.; Antharjanam, P. K. S.; Prasad, E.; Flowers, R. A., II. J. Am. Chem. Soc. 2008, 130, 7228-7229.
Table 2. Reaction of $\mathbf{3}$ with $\mathrm{SmI}_{2}$ and Additives

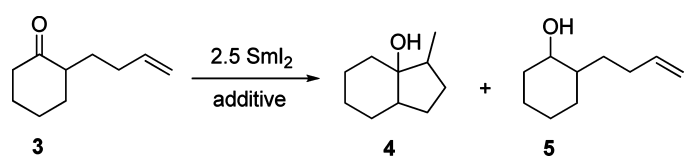

\begin{tabular}{|c|c|c|c|c|}
\hline entry & additive, equiv & time $(\mathrm{h})$ & yield $\mathbf{4}^{a}$ (cis:trans) & yield $\mathbf{5}^{a}$ \\
\hline 1 & none & 24 & NR & \\
\hline 2 & HMPA, 4 & 1 & $98(1: 19)$ & $<2$ \\
\hline 3 & $\mathrm{H}_{2} \mathrm{O}, 20$ & 1 & $62(1: 3)$ & 38 \\
\hline 4 & $\mathrm{H}_{2} \mathrm{O}, 150$ & 1 & $94(1: 3)$ & 6 \\
\hline 5 & $\mathrm{EG}, 4$ & 12 & $78(1: 3)$ & 22 \\
\hline $6^{b}$ & EG, 24 & 2 & $87(1: 3)$ & 13 \\
\hline 7 & $\mathrm{ED}, 4$ & 12 & $99(1: 3)$ & \\
\hline 8 & $\mathrm{DCH}, 10$ & 3 & $99(1: 9)$ & \\
\hline
\end{tabular}

if other additives could be used in the reaction, several additives were screened using UV-vis as a guide for iodide displacement. Diamines were shown to displace iodide (as determined by the presence of an absorbance at $480 \mathrm{~nm}$ ). Ethylenediamine (ED) and trans- $N, N^{\prime}$-dimethyl-1,2-cyclohexyldiamine (DCH) were chosen for use in the cyclization, and the data are contained in Table 2. Both additives provided quantitative yields as determined by ${ }^{1} \mathrm{H}$ NMR. Although ED provided modest stereoselectivity similar to EG and water, DCH provided good diastereoselectivity. It is likely that the increased steric bulk of DCH is in part responsible for the enhanced diastereoselectivity.

Overall, these studies demonstrate that a range of additives can be used to accelerate reactions of $\mathrm{SmI}_{2}$ through displacement of iodide ligands. The key feature for successful implementation of this approach is the use of additives that have a high enough affinity for Sm(II) to displace iodide yet do not saturate the coordination sphere inhibiting substrate reduction. We are currently examining this approach in the development of other Sm(II)-based reactions and these studies will be reported in due course.

Acknowledgment. R.A.F. thanks the National Science Foundation (CHE-0844946) for support of this work. We thank Mr. James Devery (Lehigh University) for his useful comments on the manuscript.

Supporting Information Available: General methods, experimental protocols, and spectroscopic data. This material is available free of charge via the Internet at http://pubs.acs.org.

OL101722C 